\title{
Biobibliografía de los protomártires jesuitas de América: Pedro Correia y João de Sousa
}

\author{
Biobibliography of the Jesuit proto-martyrs of America: Pedro Correia \\ and João de Sousa
}

\author{
Carlos A. Page ${ }^{1}$
}

\section{RESUMEN}

El H. Correia fue uno de los primeros lingüistas que contó la Compañía de Jesús en América. Por esos conocimientos recorrió gran parte de las tierras del hoy estado de Rio Grande do Sul, alcanzando a los tamoios, tupiniquins, ybyrájaras y carijós. La pacificación de estos últimos, como llamaban los portugueses a los guatanís, lo llevó a un martirio instigado por un español, muriendo con su compañero, el H. Sousa, cerca de la Navidad de 1554. Analizamos la bibliografía escrita en torno a estas muertes, de los siglos XVI y XVII, que se inicia a partir de un escrito del P. José de Anchieta, para luego reconstruir las vidas, sobre todo la del H. Correia, sobre la base de una serie de documentos editos que, en gran medida, le dan veracidad al relato del santo santacrucero. Las muertes de los HH. Correia y Sousa, constituyeron la validación de la presencia de la Compañía de Jesús en América, aunque la historia no dejó de ser utilizada ideológicamente en distintas circunstancias y épocas. Incluso negando, en la actualidad, el papel que cumplieron en América, que es el problema e hipótesis que presentamos.

Palabras-clave: Mártires Jesuítas, Pedro Correia e João de Sousa, Missões Jesuitas, Guayrá.

\section{ABSTRACT}

Brother Correia was one of the first linguists to have counted the Society of Jesus in America. Through this knowledge, he traveled through a large part of the lands of the state of Rio Grande do Sul, reaching the Tamilo, Tupiniquins, Ybyrajaras and Carijós. The pacification of the latter, as the Portuguese called the Guarani, led him to a martyrdom instigated by a Spaniard, dying with his companion, Brother Sousa, near Christmas in 1554. We analyzed the literature written about these deaths, from the sixteenth and seventeenth centuries, which begins with a letter from Fr. José de Anchieta, and then reconstructs the lives, especially that of $\mathrm{Br}$. Correia, on the basis of a series of edited documents that, in a large measure, give truth to the story of the blessed santacrucero. The deaths of HH. Correia and Sousa, constituted the 
validation of the presence of the Society of Jesus in America, although the story did not stop being used ideologically in different circumstances and times. Even denying, at present, the role they fulfilled in America, which is the problem and hypothesis that we present.

Keyword: Jesuit Martyrs - Pedro Correia and João de Sousa - Jesuit Missions - Guayr.

\section{Estudio biobibliográfico europeo}

Los intentos por reconstruir la historia de los jesuitas de la Asistencia de Portugal comenzaron tempranamente. Sabemos que Simão Rodrigues y Francisco Javier fueron recibidos por el rey Joao III en 1540 y a partir de entonces se establecieron en Portugal. En tanto que, nueve años después, el P. Manuel de Nóbrega arribó a las costas de Brasil, siendo con sus compañeros ${ }^{2}$, los primeros jesuitas que llegaron a América, ofreciendo al mundo los protomártires de la Compañía de Jesús en América.

La muerte de los jesuitas Pedro Correia y João de Sousa la dio a conocer, por primera vez, el P. José de Anchieta a Ignacio de Loyola por carta escrita en latín, hoy perdida, a fines de marzo de 1555. Lo hizo con información directa de testigos presenciales en el contexto de diversas noticias del Brasil (No como una carta de edificación o necrológica). En ese mismo año se publicó en Portugal $^{3}$ (Figura 1), pero en castellano, al igual que se imprimió al año siguiente en Barcelona y en 1561 en Zaragoza. En italiano se publicó en Roma en 1557 y en Venecia en 1565. Recién se tradujo al portugués con la publicación que hizo la Biblioteca Nacional de Río de Janeiro en 1877. Pero, según el P. Leite (1957, p. 174), todos estos impresos fueron resúmenes del original que nunca se publicó y está extraviado. Destaquemos que el relato, del que se basaron todos los biógrafos, es obviamente coronado por palabras laudatorias:

[...] Sofrerom a morte estes bem-aventurados Irmãos pela santa obediencia, pela pregação do Evangelho, pela paz, e pelo amor e caridade dos seus próximos, a quem foram prestar auxílio; e, para nenhuma jóia ou pérola lhes faltar na coroa, perderam a vida pela verdade e pela justiça

\footnotetext{
${ }^{2}$ Ellos eran los PP. Leonardo Nunes, Juan de Azpilcueta Navarro, António Pires y los HH. Vicente Rodrigues y Diogo Jácome. ${ }^{3}$ Copia de unas cartas de algunos padres y hermanos de la compañia de Jesus que escrivieron de la India, Japon y Brasil a los padres y hermanos dela misma compañia en Portugal, fueron recebidas el año de mil y quinientos y cincuenta y cinco. Coimbra: João Álvares, 1555.
} 
que pregavam, e finalmente pela exaltação, da sante fé, que daqui foram confessar entre os gentíos ${ }^{4}(\operatorname{LEITE}(1957$, p. 203).

Figura 1 - Portada de la primera edición de la carta de Anchieta publicada en 1555.

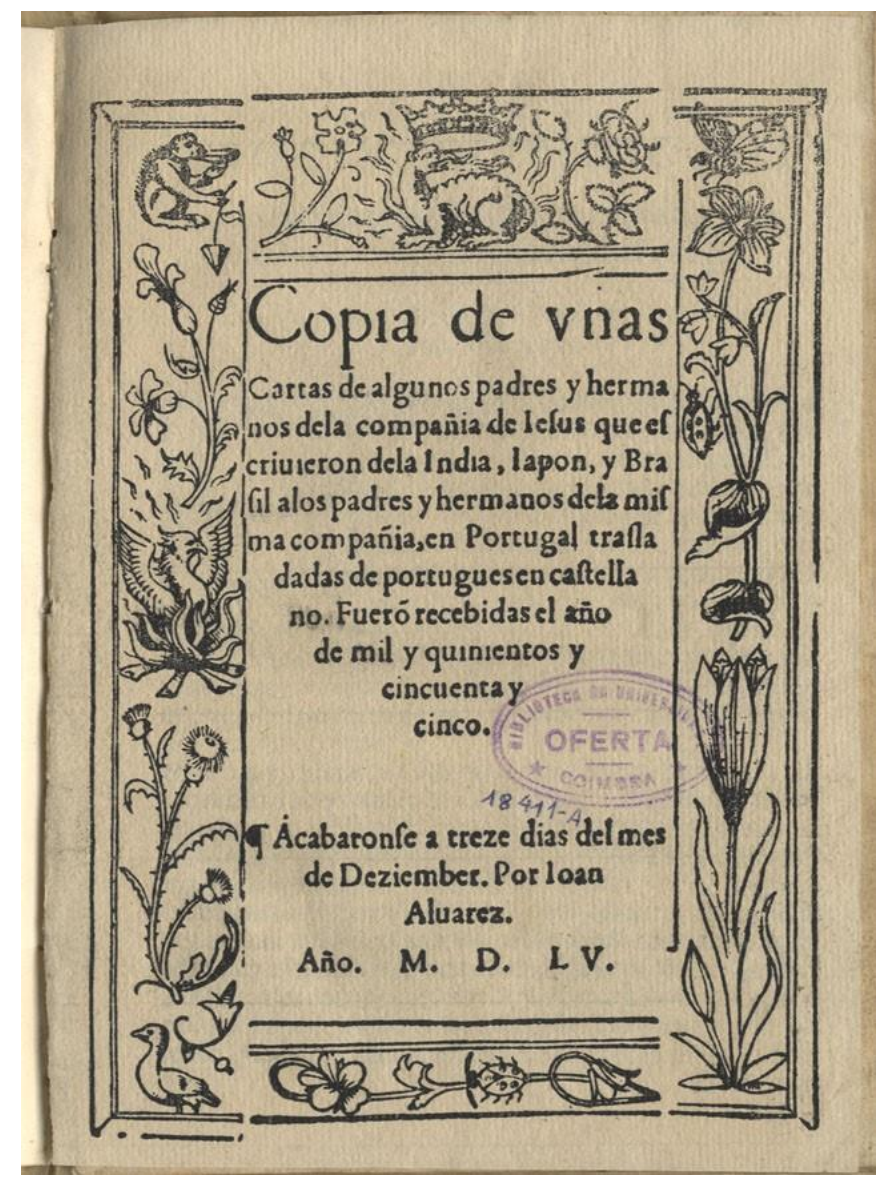

Fonte: Biblioteca Nacional de Portugal.

A bien de estas publicaciones, el primero que llevó a la imprenta un relato histórico de los protomártires, fue el español Pedro de Ribadeneira (1526-1611), de una amplia trayectoria diplomática y cargos de gobierno en la Compañía de Jesús. Residiendo en Roma compuso una biografía de Ignacio que le encargó Francisco de Borja. A partir de entonces, su producción literaria fue copiosa, discurriendo entre la historia, la hagiografía y ascética, considerado de los grandes escritores del "siglo de oro" español. Nos detenemos en la biografía de Ignacio pues es la que menciona a los protomártires americanos. La primera edición en latín es de 1572 y en castellano en 1583, aunque la definitiva corregida, es la publicada en Madrid en 1605. Este gran humanista se refirió a Correia y Sousa expresando que, al mismo tiempo en que

${ }^{4}$ Carta Do Ir. José de Anchieta ao P. Inácio de Loyola. S. Vicente, fines de marzo de 1555. 
Francia se decretaba en contra de la Compañía de Jesús, en Brasil morían: "el hermano Pedro Correa, y el hermano luán de Sosa Portugueses de nacion, yendo á predicar el Euangelio á los pueblos Ibirrajaros, fueron asaeteados de los Carijes, gente barbara y feroz, y degollados estando de rodillas en oración". Destaca que el noble Correia fue el primero que entró en la Compañía de Jesús en Brasil, donde permaneció cinco años entre los indígenas, de quienes aprendió su lengua. Mientras Del H. Sousa expresa que: "tambien fue de los primeros que en el Brasil entraron en la Compañia, hombre senzillo, y de muy sanas entrañas, que se esmeraua en las virtudes de la penitencia, humildad, y caridad"(RIBADENRYRA, 1954, p. 240-241). La mención de "degollados" es un agregado del madrileño, que no concuerda con el relato del P. Anchieta.

Le siguió a Ribadeneira el jesuita italiano P. Giampietro Maffei (1535-1603), quien publicó, en 1588, una obra que -someramente- menciona a los protomártires. Llegó a Portugal en 1579, enviado desde Roma por pedido del cardenal Henrique de Portugal. Tenía como labor escribir la historia de las conquistas y misiones portuguesas en Asia y para ello contaría con João Rebelo por ayudante. La obra tuvo varias ediciones y traducciones (MAFFEII, 1593). Le siguió el francés Pierre du Jarric en una amplia obra publicada en 1610, a lo que nos referiremos luego.

Continuó el italiano Niccolò Orlandini (1553-1606), profesor en el noviciado de Sant'Andrea al Quirinale de Roma y, profesor y rector en Nola. Regresó a Sant'Andrea en 1599 para ocuparse de escribir la historia de la Compañía de Jesús con el apoyo del P. General Aquaviva, hasta que publicó su obra en 1614, prologada por su discípulo y continuador Francesco Sacchini (ORLANDINI, 1614). Le dedica casi tres páginas a los jesuitas Correia y Sousa, comenzando con un elogio de las virtudes de ambos: "candidissimi ingenij, E innocentium morum honesto viro", dando ejemplos de su vida cotidiana y alabando el sacrificio en extensa elucubración apologética. Menciona al P. Nóbrega y a los carijós, pero de manera genérica y pomposa.

En 1642, el portugués Bartolomeu Guerreiro (1564-1642), escribió la Gloriosa coroa, que está compuesta de cuatro partes; la primera contiene la historia general de la Orden y su establecimiento en Europa, en especial en Portugal. Las tres restantes tratan de las misiones en África, la India, Brasil y Japón. De Brasil escribe, en la tercera parte "Da gloriosa coroa dos soldados valerosos da Companhia...". Se dedica a biografiar a sus mártires, precedido por una larga introducción ilustrativa y llega a los HH. Correia y Sousa, haciendo apología de otros cristianos muertos en similitud de condiciones, siguiendo con el P. Ignacio de Azevedo (GUERREIRO, 1642, p. 306).

Guerreiro fue el primer portugués que llevó a la imprenta la historia de los jesuitas del Brasil. No obstante, los antecedentes de esta labor en Portugal y sus colonias, comenzaron a vislumbrarse varias décadas antes, en 1565, cuando el secretario de la curia romana, P. Juan Polanco, ordenó al provincial Diogo Mirão que se compusieran las historias de los colegios. La orden se repitió varias veces y casi una década después comenzaron a llegar los escritos a Roma, aunque -aparentemente- no tenían como fin su publicación, ni siquiera quedaron 
registrados los nombres de los autores y todos permanecieron inéditos (RODRIGUES, 1931). Pero en la Congregación Provincial, reunida en Lisboa en 1587, se solicitó al general autorización para encargar a un escritor que redactara la historia de los sucesos dignos de recuerdo que incluyesen todas las cuestiones. Entre ellas y obviamente lo más significativo para contar, ante la falta de antigüedad de la Orden, eran los ejemplos de virtud de sus religiosos. El general Aquaviva, que a su vez preparaba en Roma una historia universal, aprobó el postulado y encomendó al provincial que escogiese a quien creyera más conveniente. De tal manera que fue designado el P. Álvaro Lobo, quien en 1591 publicó un martirologio de santos canonizados y beatificados de Portugal con información brindada por los jesuitas. En esta especie de complemento del martirologio romano manifiesta que, en otra oportunidad, publicaría otra obra que incluiría los "Varones Ilustres", pero que no llegó a la imprenta (FERNANDES, 2002). Muchos historiadores (no menos importantes) continuaron su tarea, aunque sin fortuna para publicar. Hasta que, entre 1645 y 1647, Baltasar Teles (1596-1675), afamado profesor de letras, publicó una crónica en dos tomos, en gran parte tomando como base el trabajo de Lobo (TELES, 1647), que se imprimió en 1647.

Apenas un año después de Guerreiro, comenzó a publicarse la larga obra del jesuita madrileño y calificado polígrafo Eusebio Nieremberg (1595-1658) referida a las biografías de los "varones ilustres" de la Compañía de Jesús, a los que se intentó representar como sorprendentes ejemplos de santidad. Nieremberg se destacó en sus tratados espirituales que dejaron una profunda marca en varias generaciones de cristianos. Mientras que sus obras biográficas comenzaron con la vida de Ignacio (1631) y, varios años después, la de Francisco de Borja (1644). Pero sobresalen los cuatro tomos sobre las biografías de jesuitas que continuó Alonso de Andrade. Precisamente en el tomo 2, publicado en 1644, apareció la "Vida, del Hermano Pedro Correa, que padeció martirio, juntamente con el Hermano Iuan de Sossa” (NIEREMBERG, 1644, p. 489). Exagera un tanto, como han señalado varios críticos, y no es la excepción con el H. Correia, de quien escribe: "No avia en el Brasil ningún Portugues mas poderoso que nuestro Pedro, y era el mas tirano de todos contra aquellos Indios" (NIEREMBERG, 1644, p. 489). Esclavista por excelencia, no ahorra en pavorosos calificativos que remedió ingresando a la Compañía de Jesús. Agrega que, por su sapiencia de la lengua originaria, fue maestro del resto de sus compañeros. Nieremberg resalta anécdotas de hechos que hemos visto documentados por sus contemporáneos, como por ejemplo, su accidente en la cabeza y en sus ojos, de los que sanó inmediatamente. Pues en la hagiografía no era suficiente relatar el martirio y muerte sino que los hechos, interpretados como milagros, contribuían a idealizar a los "héroes" de la cristiandad.

Volvamos a Baltasar Teles (1596-1675), otro escritor jesuita portugués que llegó a publicar exclusivamente sobre la historia de la provincia de Portugal. Fue profesor en varios colegios y alcanzó a ser provincial de Portugal (1657-1662). Si bien escribió temas filosóficos, los libros históricos sobre Portugal y Etiopía le dieron justa fama. Para su primer trabajo se nutrió de sus predecesores Álvaro Lobo y António Leite, con un estilo moderadamente barroco. La obra 
apareció en dos tomos; el primero, impreso en 1645 y el segundo en 1647. En este último hace especial referencia a la historia de los jesuitas del Brasil y coloca a los protomártires en el espacio merecido.

Como era lógico en su tiempo, ambos mártires eran considerados "benaventurados", pues murieron "honrando a Deos com a vida que por elle deram". Agrega Teles que Correia había recorrido grandes territorios con mucha dificultad, pero que le valió para aprender la lengua y recibir el afecto de los indígenas. Los dos primeros capítulos de Teles señalan las virtudes de los protomártires. Recién en el tercero cuenta que el P. Nóbrega lo envió al interior a los fines de intentar liberar a unos cautivos españoles. Incluso de una india amancebada con uno, sabiendo de la existencia de los "ibibarajas”, que se ubicaban más allá de los carijós, amigos de los españoles, y que los portugueses llaman "bilreyros". De ellos se decía que eran más pacíficos que los de la costa y que su lengua difería un poco. Pero Correia ya tenía conocimiento de los vocablos y modo de hablar, pues siempre contaba con un indígena de esta etnia a su lado. Pero los carijós tenían de enemigos a los tupíes. Y, luego de liberar a los prisioneros, comenzó a predicar la paz entre ambos enemigos. Hasta formó un pueblo con ambos. Pero una traición causó el desenlace que culminó con las vidas de los jesuitas, y Teles la relata con detalle.

\section{Vasconcellos y la iconografia de los protomártires}

Específicamente de Brasil, solo contamos para el siglo XVII, con la obra del jesuita portugués Simão Vasconcellos (1596-1671), quien dedicó suficiente espacio a los protomártires, no sin dejar de citar sus fuentes, o mejor dicho, quienes algo habían escrito de ellos.

Misionero en la América portuguesa, escribió la historia de la Compañía de Jesús del Brasil entre 1649 y 1654. La obra fue publicada en Lisboa en 1663 (VASCONCELLOS, 1865, p. 97). Pero también incluyó sendos capítulos de la historia de los mártires, antes y después de esta obra, en los libros que publica la biografía de los PP. Almeida y Anchieta (VASCONCELLOS, $1658,1672)$.

Expresa en el inicio de su historia de la Compañía de Jesús en Brasil: "filhos ambos primogénitos do mesmo Padre Leonardo, que recebera, e formara em Christo na Companhia, duas luzes das trevas da gentilidade, ambos nos annos mais floridos, guias dos mais occultos sertões, exemplares de Missionários, espelhos de toda a virtude" (VASCONCELLOS, 1865). 
Escribe que sigue la carta de Anchieta, por su autoridad y por haber tenido noticias ciertas al ser contemporáneo de los mártires. Inferimos que es su texto base, al que agrega aportes de otros autores (que cita al final). Quizás algunos datos estén recargados de entelequias literarias. Habla de las costumbres de los ybyrajáras, a los que había alcanzado el P. Correia, aprendiendo incluso su lengua y que, varios años después, fueron reducidos por el jesuita portugués P. Manuel Ortega en las cercanías de Villarrica (PAGE, 2016). Es este uno de los motivos por los que fue enviado, otro -señala Vasconcellos- era por unos náufragos españoles que llevó el P. Nunes desde Porto dos Patos (Florianópolis) a São Vicente y desde allí regresarían para luego continuar por tierra al Río de la Plata. Pero antes, el P. Nóbrega envió al H. Correia para apaciguar a los exaltados indígenas de la región a los fines que aquellos pudieran pasar. El tercer motivo fue que la guerra constante entre tupis y carijós solo podría ser sosegada por el $\mathrm{H}$. Correia, por su especial deferencia con los indígenas y como "anjo da paz". Se concentra, finalmente, en los detalles del martirio, siguiendo siempre al P. Anchieta, incluso citando entre comillas ciertos pasajes de su texto. Sigue describiendo someramente la vida del H. Correia, un enriquecido portugués que basó su fortuna en la trata de indígenas y que, al escuchar las prédicas del P. Nunes cuando llegó a São Vicente, quedó arrepentido de sus actos y se incorporó a la Compañía de Jesús, comparándolo con la conversión de San Pablo. Por primera vez un autor menciona que consultó los archivos jesuíticos, como también la relación de la vida que escribió Teles, Orlandini, Maffei y Niéremberg que, en definitiva, también siguen a Anchieta ${ }^{5}$.

En cuanto a las representaciones(PAGE, 2017) que se hicieron de los mártires, la primera que conocemos es la publicada en las portadas de los dos primeros tomos del libro del P. Pierre du Jarric, en 1610 (JARRIC, 1610). Profesor de filosofía y teología moral en Burdeos, el jesuita francés Jarric (1566-1617) no pudo viajar a las misiones y en su lugar escribió sobre ellas en tres tomos, brindando una imagen amplia de las empresas jesuíticas, principalmente de la Asistencia de Portugal. En cuanto a las ilustraciones de la portada, tanto grabados, viñetas y títulos, corresponden a L. Gaultier ${ }^{6}$, quien muestra los martirios de los HH. Correia y Sousa entre nueve ilustraciones de otros misioneros. Se representan a los mártires suplicando de rodillas frente a cinco indígenas que los amedrentan con sus flechas (Fig. 2). El P. Jarric además menciona la historia en el tomo 2, desde el ingreso en la Compañía de Jesús del H. Correia, los enfrentamientos entre indígenas y finalmente el relato del martirio (JARRIC, 1610, t. 2, p. 272).

\footnotetext{
${ }^{5}$ En ARSI, Lus. 59, ff. 37-42 se encuentra un manuscrito anónimo y sin fecha titulado: "Vita dei Fratelli Pietro Correia e Giovanni di Sousa primieri Martiri dei Brasile", que al citar a Vasconcellos (1663), y otros autores que lo presidieron, lo ubicamos posterior al mismo.

${ }^{6}$ Se refiere al célebre Leonardo Gaultier (Mainz, 1561 - París, 1635), dibujante y grabador, hijo de Pierre, comerciante orfebre de París. Trabajó principalmente en Lyon y París. El abate de Marolles poseía más de 800 estampas suyas. Entre ellas, retratos de Enrique IV de Francia, Henry, duque de Montpensier; Jacques Amyot, obispo de Auxerre y varios temas como la coronación de María de Medici, conjunto de profetas, apóstoles y evangelistas, vistas de París, etc.
} 
Figura 2 - Portada del libro del P. Jarric publicada en 1610 con el diseño del artista Gaultier

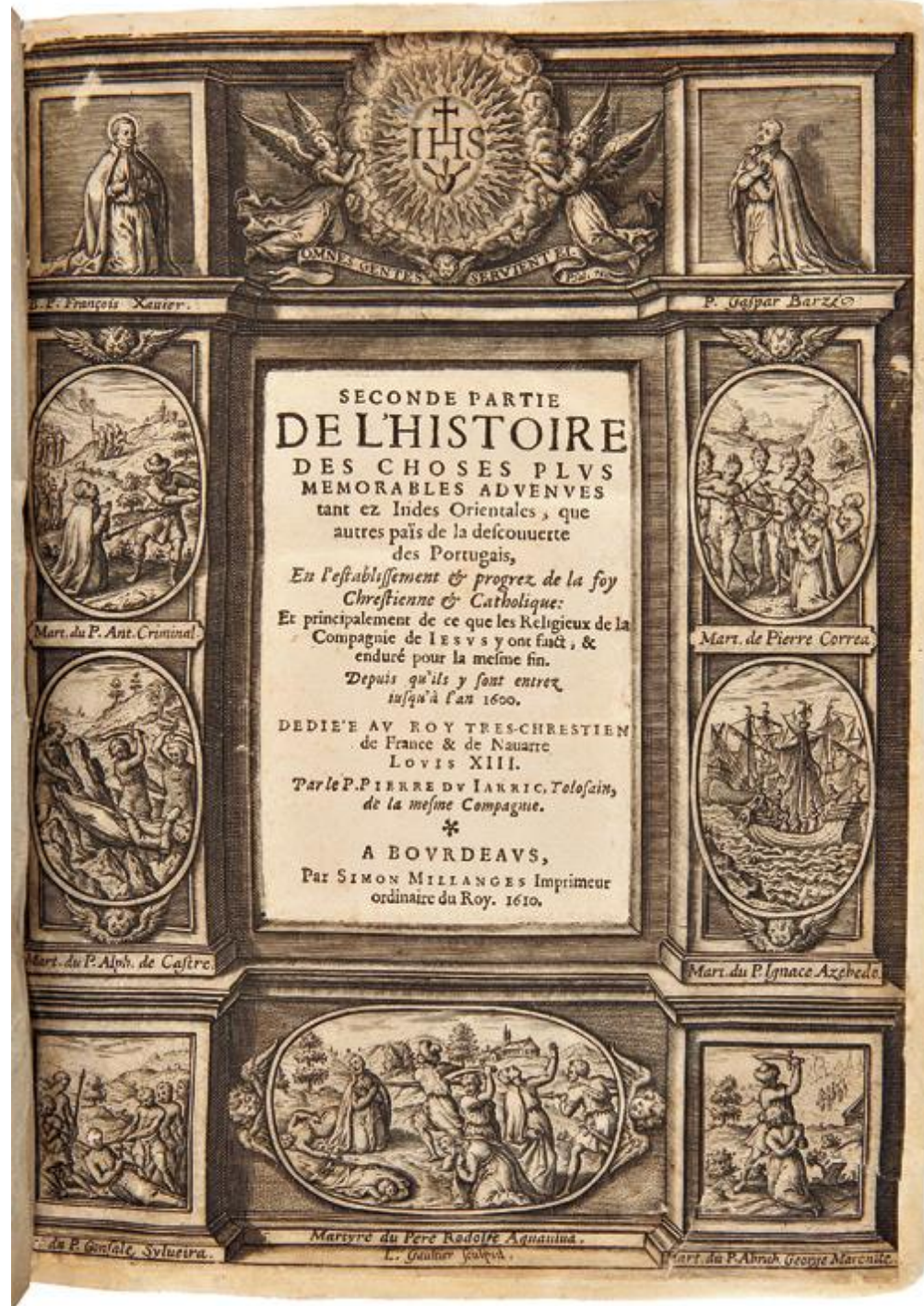

Fonte: Biblioteca Nacional de Portugal

En medio de incontables publicaciones del siglo XVII, quien también publica los acontecimientos del martirio y a su vez introduce una ilustración del mismo, es el bohemio Matthias Tanner, rector de la universidad imperial y provincial de Bohemia que publica en 1675 (TANNER, 1675). La ilustración es una estampa del grabador alemán Melchior Küsel y representa a los HH. Correia y Sousa en el momento de ser flechados. Aunque la imagen es de los dos personajes atacados simultáneamente, como los representó Gaultier, cuando en realidad primero fue el $\mathrm{H}$. Sousa. Un error grave de Tanner es que a continuación de este relato, hace otro de dos hermanos mártires del Brasil desconocidos y que en realidad nunca existieron. 
Los rostros imaginarios de ambos mártires también fueron representados a fines del siglo XVII por autor desconocido, en la iglesia de San Salvador de Bahía, más específicamente en el casetonado del techo de la sacristía, donde se los pintaron en medio de floridas tarjas. En todo ese techo se incorporan veintiún sacerdotes y coadjutores jesuitas canonizados y beatificados hasta el momento de la decoración, colocados en forma de cruz. En los cuatro cuadros restantes se pintaron mártires de la Asistencia de Portugal. Entre ellos Pedro Correia y João de Sousa, ubicados en el extremo sur de la sacristía. Aunque afirma De Moura Sobral, que Correia es la imagen invertida de San Pablo Miki (MOURA SOBRAL, 2001), uno de los mártires crucificados del Japón en 1597.

También, Benedito Calixto (1853-1927) pintó una serie de obras en la iglesia de Santa Cecilia en São Paulo. Dos de ellas sobre la historia de Pero Correia, en su época de bandeirante (1910) y en su martirio (1912), que fueron realizadas como parte de las reformas del templo impulsadas por el arzobispo Duarte Leopoldo e Silva. Los paneles se ubicaron sobre las entradas de la capilla del Santísimo Sacramento y de la sacristía, resaltando la doble condición de bandeirante y jesuita en una clara tentativa de exaltación de ese pasado (TOLEDO ROMANO, 2009; PHILIPPOV, 2013), aunque engrandecen la muerte de una manera que no fue, es decir que introducen porra y lanzas que en realidad no se mencionan en los relatos, sino que la muerte fue por flechas. Historiadores de arte brasileros coinciden que su representación constituye una exaltación a los valores heroicos que se le querían imponer a los bandeirantes, desde instituciones históricas y de la propia élite. Una monumentalización del pasado paulista que ingresó al siglo XX como la provincia más rica del Brasil, pero sin un pasado glorioso que se exalta con la figura de los mártires

\section{Noticias preliminares: "o melhor lingua do Brasil"}

Pedro Correia vivía en Brasil cuando llegaron los jesuitas en 1549. Más específicamente, ya se encontraba en 1534 (LEITE, 1956). Pero poco se sabe de su vida antes de ingresar a la Compañía de Jesús, aunque en una carta que le hace escribir el P. Nóbrega para los HH. de Portugal, cuenta en tercera persona que fue de visita por la costa, recordando una anécdota:

vino una vez el Hermano Pero Correa, estando aún en el mundo, y, queriéndole matar los gentiles, se hizo hijo de una destas indias y de un hombre blanco, la qual por pensar que era su hijo hizo que le matassen. Esta mujer por aver ya aquí visto este Hermano con el Pe. Leonardo 


\begin{abstract}
Núnez nos dixo que su hijo era Abbaré, que quiere decir abbad sancto verdadero, y luego pedió al Padre (Nóbrega) que la levasse adonde estava su hijo. Y el Padre la truxo con un su hijo y una hija preñada que ya parió aquí en San Vicente y se baptizaron todos (LEITE, 1956, p. 429).
\end{abstract}

En una declaración de 1550, Correia expresa que Pedro do Campo era "grande amygo" y que "tinha com elle huú comtrato feyto pera com sua filha, ho quall teme em sua maão". Pedro de Campo Tourinho había sido agraciado por João III con la capitanía de Porto Seguro en 1534, tomando posesión de las tierras al año siguiente. Correia se iba a casar con su hija Leonor, aunque ésta finalmente contrajo matrimonio con Gregório da Pesqueira, pues Pedro habría de ingresar a la Compañía de Jesús (LEITE, 1956, p. 44).

El P. Nóbrega cuenta que en São Vicente, antes que Correia entrara a la Compañía, éste demandó por 2.600 ducados al capitán general de la capitanía Bras Cubas, por una deuda que tenía con él. Al ingresar a la Compañía y donar sus bienes a la misma, el P. Leonardo Nunes habló con el moroso, quien no solo negó la deuda sino que dijo era él a quien se le debía. Lo cierto es que no tuvo escapatoria y Cubas huyó a Portugal ${ }^{7}$ (LEITE, 1956).

A propósito de la donación, o renuncia de bienes, que hizo a los jesuitas, sabemos que -al menos- para 1542 moraba en São Vicente, año en que recibió unas tierras que donó a la "cofradía dos Meninos de Jesús" de la mencionada villa. Efectivamente, el P. Leite publica la carta de confirmación de las tierras donadas por el H. Correia, fechada el 22 de marzo de $1553^{8}$ (LEITE, 1956, p. 459-464). Lo hizo ante el capitán y oidor António de Oliveira, quien expuso en el documento que las tierras que donaba, eran las que el capitán Gonçalo Monteiro, teniente del donatario, le cedió a Correia. Una ubicada en la isla de São Vicente, antes propiedad de un maestre llamado Cosme, quien al no dejar descendencia, dejó vacante. Abarcaban desde el sitio conocido como "Porto das Naos", junto a las tierras de António Rodrigues, uno de los primeros pobladores de la región, hasta las del, por entonces difunto, Fernão de Morais. Las otras tierras que entregaba Correia a los jesuitas, habían sido originalmente para él y su hermano, que pensaba llegar al Brasil, pero no lo hizo. Consistían en una isla, la mayor de tres, ubicada en la desembocadura del río Guaraú (Santa Catalina), donde estaba la población, por entonces indígena, de Peruíbe (Tapiiranema). La llamaban "Ilhas de Guaraú" y la mayor que se concedió a Correia se conoce como "Ilga Grande". Ambas posesiones fueron registradas en el "Livro do Tombo", donde el escribano asentaba las propiedades de tierras?

\footnotetext{
${ }^{7}$ Carta: Do P. Manuel da Nóbrega ao P. Luis Gonçalves da Cámara, Lisbora. S. Vicente, 15 de junio de 1553: 501.

${ }^{8}$ Carta: Confirmação das terras doadas pelo Ir. Pero Correia ao colégio de S. Vicente. S. Vicente, 22 de marzo de 1553.

${ }^{9}$ Esta donación fue nuevamente confirmada el 10 de diciembre de 1562 (Leite SJ, Serafim (1960). Monumenta Hitorica Societatis Iesu. Monumenta Brasilae IV. Roma: Monumenta Historica SI: 47. Permuta de Terras, confirmação e registro da sesmaria de Geraibatiba (Piratininga). S. Vicente, 14 de marzo de 1564.
} 
Pues parece ser que Correia había hecho fortuna y seguimos palabras de Vasconcellos, quien afirma que además de ser noble era: "o mais poderoso dos moradores". Su fortuna la hizo: "salteando, e cattivando Indios por mar, e por terra, de que enriquecía sua casa" (VASCONCELLOS, 1865, p. 101). Y lo de noble, como lo define el P. Anchieta, en algunos casos fue exagerado, al punto que el historiador francés Hacques Cretineau-Joly (1803-1875), sacerdote que dejó los hábitos, escribió en 1849 que pertenecía a la familia real de Portugal (CRETINEAU-JOLI, 1853).

Estando Correia en Bahía conoció a los PP. Manuel da Nóbrega y Leonardo Nunes. Se estima que para fines de 1549 y comienzos de 1550 habría ingresado a la Compañía de Jesús, pues la única referencia que se tiene de su actividad, es que posiblemente formó parte de la expedición a São Vicente con el P. Leonardo, quien llevó a una decena de niños para crear el "Colégio dos Meninos de Jesus", a los que se sumaron otros, provenientes de los campos de Piratininga, a los que enseñó gramática y a -algunos- latín ${ }^{10}$. São Vicente era un sitio que ya conocía Correia y fueron bien recibidos justamente por su regreso. Así como lo expresa el P. Nunes: "por causa dalguns Irmãos que já aque estiveram", refiriéndose al H. Correia. Esto también beneficiaría el desarrollo de la actividad pastoral con los indígenas, pues como escribe el P. Nóbrega, el H. Correia era: "virtuoso e sábio e o melhor lingua do Brasil". Además de expresar que se iba a ordenar sacerdote y contara con él para su misión al Paraguay, de la que estaba muy entusiasmado (LEITE, 1956, p. 45).

Una vez en São Vicente, comenzaron con las misiones volantes, obviamente readaptadas a la realidad americana. Quizás, una de las primeras salidas es la que cuenta el propio H. Correia $^{11}$ en 1551 al P. Nunes Barreto, quien partía a la India ese año. Describe la misión que hicieron durante quince días por los alrededores de la villa y por el río Tieté, entre ocho y nueve días en "cascas de paos". El H. Correia era el intérprete, hablando con todos los indígenas principales. Luego acudían a la villa donde el $\mathrm{H}$. Correia predicaba en su lengua los jueves, domingos y festividades religiosas. También menciona a la india Isabel Dias, con otro nombre de Bartira o Mbci, hija de Tibirica, que vivía con el portugués João Ramalho, excomulgado por tener esposa en Portugal y quien ya tenía bisnietos de Isabel (LEITE, 1956, p. 219) ${ }^{12}$. En otra oportunidad, volverán por el río Tieté donde encontrarán a un cristiano que vivía entre ellos hacía casi una década. Fueron con el P. Nunes, quien enviaba al H. Correia a predicar a los indígenas. Éste veía como una dificultad que vivían muy dispersos y en cada pequeña aldea había un principal, que si hubiera entre ellos "rey", pues: "Y sy oviera rey, él convertido, fueron todos, mas ya que no lo ay, para convertirlos ha de ser necessario pasar aquá muchos Hermanos,

\footnotetext{
${ }^{10} \mathrm{El}$ colegio fue inaugurado solemnemente con la prédica del P. Nóbrega el 2 de febrero de 1553.

${ }^{11}$ Se conocen del H. Correia cinco cartas, fechadas entre 1551 y 1554 y dirigidas dos al P. Melchor Nunes Barreto, quien alcanzó a ser viceprovincial de la India, dos al provincial Simão Rodrigues y la última al P. Brás Lorenço, que se encontraba en Espiritu Santo. Algunas cartas fueron escritas a pedido de los PP. Nóbrega y Nunes, y una es anónima pero de evidente texto del H. Correia. Además de las noticias que brindan sobre los acontecimientos del momento, contienen una rica información etnológica.

${ }^{12}$ Carta: Do Pero Correia ao P. Balchior Nunes Barreto, Coimbra. S. Vicente 8 de junio de 1551.
} 
porque las tierras son mui grandes y ay muchas almas por todas ellas perdidas" (LEITE, 1956, p. $229)^{13}$.

En una carta de un coadjutor a los coadjutores de Portugal, del 10 de marzo de 1553, se cuenta que vino a São Vicente el P. Nóbrega con el gobernador Tomé de Sousa, el P. Francisco Pires y cuatro niños. Continúa manifestando que el H. Correia se embarcó con el P. Nóbrega y el gobernador hacia Puerto Seguro, donde estaba el P. Navarro, quien ya había aprendido la lengua de los naturales y predicaba por los alrededores. Fueron muy bien recibidos y los pobladores se ofrecieron a construir una escuela para los niños indígenas. Siguieron con cierta prisa a Espíritu Santo, donde el P. Alfonso Bras había abierto el Colegio de Santiago en 1551. Regresaron a São Vicente, donde predicó el P. Nóbrega, mientras que el gobernador, como lo había hecho en los otros sitios, dejó importantes limosnas a los jesuitas. El viaje continuó hacia Río de Janeiro, tierra de los tamoios, donde el gobernador pretendía fundar una población portuguesa. Siguieron por un río donde el H. Correia predicaba en las aldeas en lengua de los indígenas y les enseñaba a cantar a los niños. De allí bajaron al sur unos 150 km, en Angra dos Reis, donde el P. Nóbrega enfermó por el intenso calor y al llegar a São Vicente, el P. Nunes lo embarcó hacia Bahía, pero una tempestad los hundió, aunque lograron salvarse. Luego de estos viajes, comenzaron a pergeñar su partida a Asunción y en el camino fundar una ciudad con los indígenas. Pero el gobernador no se lo permitió, temiendo que se despoblara São Vicente (LEITE, 1956, p. 425) ${ }^{14}$.

Otra carta, con igual fecha, envió el P. Correia al provincial de Portugal, por encargo del P. Nóbrega, informando sobre los "males del Brasil". Comienza relatando la poca afortunada visita de Gomes Ribeiro, visitador del obispo, que había impuesto penas en dinero por "excesos", con lo cual escribe: "la iglesia quedó muy desacreditada" y en vez de convertirse a vida cristiana se profundizó la vida en pecado, como el mencionado João Ramalho, a quien el "alguacil de los clérigos", le tomó un hijo por esclavo. Las represalias también fueron para los jesuitas, a quienes los indígenas acudían para evitar ser esclavizados, en tanto que los portugueses los amenazaban con incendiar sus casas y ni dudaban en entrar y maltratar a sus esclavos indígenas a límites extremos. Un verdadero caos retrata el $\mathrm{H}$. Correia, agregando que había sido la causa para el exacerbado odio a la Compañía de Jesús por parte de los europeos. También se siente consternado el H. Correia por la decisión del gobernador de no dejarlos ir al Paraguay y prepara un viaje a Bahía, aunque resignando su oficio a seguir enseñando en su lengua a los hijos de los indígenas en el colegio de São Vicente. Por eso le solicita libros al provincial, pero que no sean en latín que no entiende, sino en portugués. No solo eso sino que le menciona varias obras de Constantino Ponce de la Fuente, un ilustrado sacerdote de ascendencia hebrea que llegó a ser capellán de Carlos V e intentó ingresar a la Compañía de Jesús, aunque luego que se le encontrara una biblioteca prohibida, fue acusado de protestante en Sevilla y encarcelado hasta morir. El H. Correia se refería a los libros: Suma de la doctrina

\footnotetext{
${ }^{13}$ Carta: Do Ir. Pero Correia ao P. Simão Rodrigues, Lisboa. S. Vicente Junio de 1551.

${ }^{14}$ Carta: De um Irmão do Brasil aos Irmãos de Portugal. S. Vicente 10 de marzo de 1553.
} 
cristiana (1543), Exposición del primer salmo de David (1546), Confesión de un pecador (1547), Catecismo cristiano (1547) y Doctrina Cristiana (1548). No solo estos pedidos muestran un alto conocimiento de la literatura religiosa en boga, sino otros como el Flos Sanctorum que inspiró a Ignacio y que fue impreso en lengua portuguesa en 1513 y el Vitae Patrum, un muy conocido libro hagiográfico, verdadera enciclopedia de los primeros cristianos que tuvo múltiples traducciones; añadiendo en la carta: " $y$ otros de que pudiese sacar grandes exemplos con mucha doctrina para estos gentiles, los quales spero antes que muera ver a todos christianos. A pesar de esta última nota optimista, lo más interesante de la carta es la teoría de "poner a los indios en necesidad", que según expresa, venían conversando con el P. Nóbrega, con el objeto de "obligar a ser christianos y a se subjectar a dar obediencia al Rei y a sus justicias." Consistía en que, bajo pena de muerte, ningún europeo les diera cosa alguna si no se hicieran antes cristianos. Por ejemplo, herramientas para sus cultivos, pues sin ellas morirían de hambre "y el hambre es la guera de cada día, y em poco tiempo los a de vencer". La otra alternativa era educar a los niños indígenas " $y$ los biejos fuéranse gastando en sus malas costumbres y los moços quedaran en posesión de la tierra, y se hiziera una nueva christiandad". Pero explica que, como las casas de los jesuitas eran tan pobres, reconoce que esta última alternativa era muy poco viable (LEITE, 1956, p. 433) 15 .

El P. Nunes cuenta que era común que los blancos tomaran cautivos a los indígenas y que había logrado liberar a algunos que, por orden del P. Nóbrega, llevó primero a São Vicente y luego a los campos de Piratininga. Para este sitio decidió que lo acompañaran los HH. Correia y Manuel de Chaves (LEITE, 1956, p. 222-223) ${ }^{16}$, por el conocimiento de la lengua que tenían ambos. Predicaron y juntaron a unos cristianos en una ermita, la que luego fue Villa de Santo André. Continuaron viaje y regresaron a São Vicente, donde el P. Nunes determinó hacer una casa donde se congregaron ocho $\mathrm{HH}$. Levantaron una iglesia de madera, que concluyeron el 20 de junio de 1550 (LEITE, 1956) ${ }^{17}$. Templo del que se informa a Portugal unos años después: "tenemos la mejor yglesia que ay en el Brasil, según todos dizen", con mucha actividad y donde el H. Correia: "predica todos los domingos a la tarde en la iglesia en la lengoa de la tierra. Viene la más gente de la Villa a oírle que viene por la mañana, ultra los esclavos y Indios de la tierra" y que tenían un coro con un buen número de niños indígenas, cuyo maestro era el P. Francisco Pérez $(\text { LEITE, 1956) })^{18}$.

Es conocido que las noticias que recibió el P. Nobrega sobre las relaciones entre los indígenas y españoles de Asunción, como de las pisadas y camino de Santo Tomás, lo motivaron para viajar a São Vicente. Otra de sus medidas fue trasladar la casa de los niños a Piratininga, sitio: "escala para muchas naciones de los indios". Arribó el P. Nunes con el P.

\footnotetext{
${ }^{15}$ Carta: Do Ir. Pero Correia ao P. Simão Rodrigues, Lisboa. S. Vicente 10 de marzo de 1553.

${ }^{16}$ Manuel de Chaves (Vila de Moreira da Maia, c. 1514 - Sao Paulo de Piratininga, 1590). Entró en la Compañía por 1550, siendo considerado de las dos mejores lenguas con que contaba el P. Nóbrega en la provincia. Murió casi ciego, aunque sin dejar de recorrer las aldeas de indígenas.

${ }^{17}$ Carta: Do P. Leonardo Nunes aos Padres e Irmãos de Coimbra. S. Vicente, noviembre? de 1550.

${ }^{18}$ Carta: De um Irmão do Brasil aos Irmãos de Portugal. S. Vicente, 10 de marzo de 1553.
} 
Antonio Rodrigues, el 29 de agosto de 1553, ofreciendo con "grande acto solene dos 50 catecúmenos de Piratininga", aunque poco antes había pasado el H. Correia y también varias veces el P. Nunes (LEITE, 2004, p. 93). El provincial es insistente y claro:

"y en el Paragai, ciudad de los castellanos, 500 hombres tienen sobiectos a los gentiles Carijós, que tienen más de 300 legoas de tierra, y no los subiectan al jugo de Christo, sino al de su codicia y tiranía, maltratándolos y haciéndolos servir peor que esclavos, tomándoles sus mugeres e hijos e hijas, y quanto tienen. Diga V.R. a Su Alteza que si quella ciudad quedare suya, mande proveer en breve de justicia, y se mandare gente por la tierra adentro leven a N. Señor consigo y un capitán zeloso y virtuoso" (LEITE, 1956, p. 495) ${ }^{19}$.

Es evidente que para el P. Nóbrega, Asunción quedaba dentro de los límites de Brasil, donde se encontraban gran cantidad de indígenas. Lo mismo pensaba el capitán Juan de Salazar, quien escribía de São Vicente al Conselho Real de Indias manifestando que reconocían al Paraguay y el Río de la Plata como del rey de Portugal. Por su parte, Joao III es quien, preocupado, considera que el emplazamiento de la ciudad de Asunción era una provocación de Carlos V, y manda a investigar en secreto las circunstancias de su situación.

Mientras tanto, también el P. Nóbrega se refiere a la ordenación de sacerdote del $\mathrm{H}$. Correia, para lo cual lo envía a Bahía con el P. Nunes (LEITE, 2004) ${ }^{20}$ y escribe:

El Hermano Pero Correa es acá grande instrumento para por él N. Señor obrar mucho, porque es virtuoso y sabio, y la mejor lengua del Brasil. Tiene partes para se aver de ordenar de missa, pero tiene impedimento que no puede ser sin dispensación y los nuestros poderes no se extenden a sus casos, que son muerte voluntaria de algunos indios gentiles desta tierra. Se el Obispo no los tiene, como se dezia que sperava por ellos, haga V.R. averlos, porque siendo de missa hará mucho más fruto en las confesiones $^{21}$ (LEITE, 1956, p. 423).

En otra carta, despachada cuatro meses después, expresa que envió al H. Correia:

${ }^{19}$ Carta: Do P. Manuel da Nóbrega ao P. Luis Gonçalves da Cámara. S. Vicente, 15 de junio de 1553.

${ }^{20}$ Debían además recibir a la nueva y tercera expedición que llega a Bahía el 8 de mayo de 1553 con los PP. Luiz da Grã, Lorenço Braz y Ambrósio Pires, además de los HH. José de Anchieta, João Gonçalves, António Blasques y Gregório Serrão (LEITE, 2004).

${ }^{21}$ Carta: Do P. Manuel da Nóbrega ao Simão Rodrigues, Lisboa. S. Vicente, 12 de febrero de 1553. 
a la costa y las casas, por razón de la mucha autoridad y crédito que tiene con la gentilidad de todas las partes, y se ordenare de missa si el Obispo ya tuviere poder para dispensar con él, sobre homicidios voluntarios que tiene de algunos indios desta tierra. Y si el Obispo no tiene tal poder, de la Baya escrivirán para que lo ayan del Papa, para él y para todos los más destas partes (LEITE 1956, p. 494)22.

Es decir que, para obtener el sacerdocio, tenía en contra su pasado como bandeirante y solo podía ser dispensado por el flamante primer obispo del Brasil Pedro Fernandes Sardinha, y si éste se excusaba, tendría que acudir al pontífice Julio III, a quien le escribirían desde Bahía. Y así se hizo, solo que Correia murió antes de que se tomara la decisión y que seguramente sería favorable pues las muertes de indios "gentíos" se condonaban.

En la última carta que se conoce que escribió el P. Correia al P. Brás Lorenço se especifican algunas novedades de aquella primera mitad de 1554. Curiosamente, y lo nota Leite, lo hace en tercera persona: "nuestro Padre Nóbrega mandó un Hermano que sabe alguna cosa de la lengua por su precursor por el sertán dentro a predicar la palabra del Señor"23(LEITE, 1957, p. 63-72). Se refiere a él mismo, refiriendo que "el demonio" lo quiso matar de camino a Maniçoba o Japiúba, aldea donde por ese tiempo contaba con escuela de gramática y "están dos Padres y Hermanos"24. Fue derribado con dos palos: "de treynta o quarenta palmos en largo y grosura de una pierna en cima de la cabeça, que todos los que lo vieron juzgaron por muerto". Lo curaron, pensando que tenía la cabeza quebrada, y solo al otro día: "quedó tan sano como que no tuviera anda". Luego, el P. Nóbrega fue hacia donde estaba el H. Correia. Describe a continuación cómo avanzaban: "quando entravan en algún lugar huno de los niños llevaba una cruz pequeña alevantada y ivan cantando las letanias por una cierta manera muy buena; y luego los niños de los lugares se ayuntavan con ellos, y toda la gente se maravillaba mucho de cosa tannueva" (LEITE, 1957, p. 67) ${ }^{25}$. Por eso eran bien recibidos y mejor despedidos, al punto que muchos niños dejaban la aldea y se iban con los jesuitas. Se juntaron en un sitio donde los indígenas iban a matar y comer a sus esclavos. Los jesuitas trataron de impedirlo pero no pudieron, aunque a escondidas los bautizaron, al tiempo que predicaban a "corderos como a los carniceros", presenciando los asesinatos. Después llegaron unos españoles de Asunción junto a muchos carijós, que justo se toparon con unos Tupinaquins a quienes, sin más, mataron al grito de: "Matad carniceros, que nuestra carne hedionda podéis matar mas las nuestras almas yrán a ver a su Criador" ${ }^{26}$ (LEITE, 1957, p. 68). Para peor y por otro camino, entraron unos cincuenta o sesenta carijós con tres españoles y también les dieron muerte, excepto a un español que alcanzó a los jesuitas. El P. Nóbrega envió al H. Correia a buscar a los cristianos sobrevivientes.

\footnotetext{
${ }^{22}$ Carta: Do P. Manuel da Nóbrega ao P. Luis Gonçalves da Cámara, Lisboa. S. Vicente 15 de junio de 1553.

${ }^{23}$ Carta: Do Ir. Pero Correia ao P. Brás Lorenço, Espiritu Santo. S. Vicente, 18 de julio de 1554.

${ }^{24}$ Los PP. era Francisco Pires y Vicente Rodrigues. De los HH. solo se identifica a Gregório Serrão (LEITE, 1957, p. 71) Carta: Do Ir. Pero Correia ao P. Brás Lorenço, Espiritu Santo. S. Vicente, 18 de julio de 1554.

${ }^{25}$ Carta: Do Ir. Pero Correia ao P. Brás Lorenço, Espiritu Santo. S. Vicente, 18 de julio de 1554.

${ }^{26}$ Carta: Do Ir. Pero Correia ao P. Brás Lorenço, Espiritu Santo. S. Vicente, 18 de julio de 1554.
} 
No solo logró rescatarlos sino que apaciguó las pasiones asesinas de los indígenas. Regresaron a Piratininga por el mes de julio de 1554, donde habían congregado a varios indígenas convertidos. Además de levantar una capilla y una escuela de primeras letras a cargo de los HH. António Rodrigues y José de Anchieta.

\section{El martirio: la hora de la "santa muerte"}

El final se aproximaba y -como dijimos- el P. Anchieta le escribió a Ignacio, contándole lo ocurrido cuando ya se había consumado el martirio. Relata que la expedición que llevó a los HH. Correia, Sousa y Fabiano partió el 24 de marzo de 1555. A fines de ese mes recibió carta del $\mathrm{H}$. Correia, quien escribe que no solo fue bien atendido por los indígenas donde había sido destinado, sino que estos estaban muy predispuestos a formar una gran aldea donde habitar y ser instruidos, liberando a un castellano cautivo. Los indígenas a los que se refiere eran los ybyrájaras, con quienes estuvo un tiempo y aprendió las variantes de su lengua. Llegó a un rio llamado "Cuparagay", en las proximidades de Cananeia e Iguape, donde se encontraría con unos españoles. Siguió camino con ellos, dejando en "Cuparagay" al español liberado y al H. Fabiano de Lucena para que lo curase, y predicase entre aquellos indígenas. Partió con el H. João de Sousa y dos indígenas hacia la tierra de los carijós por el camino del Piabiru, debiendo volver para Navidad, como le había ordenado el P. Nóbrega. Recorrieron un largo trayecto predicando el evangelio entre ellos, como también persuadiéndolos de que hicieran las paces con sus enemigos los tupis. A pesar de una enfermedad del H. João, siguieron avanzando hasta que se cruzaron -en el mes de noviembre- con un español que vivía con los carijós y tenía autoridad entre ellos, aconsejándoles que les hicieran la guerra a los tupies. No solo eso, sino que también arengaba a los indígenas, diciéndoles que: "o Irmão Pero viera ali para abrir o caminho, por onde os inimigos os haviam de atacae, e que até trouxera arcos para os matarem"(LEITE, 1957). Pero la mayoría, decía el H. Pedro a un portugués que lo acompañaba, que: "nunca vira Indios tão preparados para todo o bem". Sin más, decidieron regresar con una docena de carijós "dos principais". Insistimos en que estos hechos fueron relatados a los PP. Nóbrega y Anchieta por el portugués, del que se desconoce el nombre, en su lecho de muerte. Precisamente éste y el español escucharon de boca de unos indios que los dos que vinieron con los HH. los habían matado y se los comerían. Esos mismos indígenas se volvieron primero- en contra del H. João, al que comenzaron a tirar flechas, cayendo de rodillas en súplica hasta morir. Viendo esto, el $\mathrm{H}$. Pero comenzó a dialogar con los indígenas para frenarlos, pero escribe Anchieta: 
Em lugar de resposta, foi varado pelas frechas dos Indios; mas nem por isso deixou de lhes continuar a falar até que, não podendo já suportar a dor, deixando cair o bordão que levava na mão e apartando os olhos dos Indios, se ajoelhou e foi morto enquanto encomendava o seu espirito a Deus. Mortos os dois Irmãos, tiraram-lhes a roupa e abandonaram os corpos para serem devorados pelas aves e feras ${ }^{27}$ (LEITE, 1957, p. 202-206).

La muerte, reflexiona el P. Leite, debe haber tenido lugar por el camino recorrido en diciembre de 1554, reconociendo que en el Menologio del Brasil se da la fecha de 3 de noviembre y, en las necrológicas de Portugal el 16 de noviembre, según fuentes del Archivo de la Compañía de Jesús de Roma. La noticia recién se conoció en São Vicente en febrero de 1555 y lo comunicó Ignacio al P. Simão Rodrigues el 29 de febrero de 1556 y a Pedro de Ribadeneira el 3 de marzo del mismo año.

El relato -como dijimos- fue trasmitido por el portugués y los que llegaron a São Vicente, quienes unánimemente afirmaron que los carijós fueron incitados por el español, justamente porque los jesuitas querían disuadir a los indígenas de no hacer la guerra que fomentaba aquel. ¿Quién era el español? No se conoce su nombre, sí que había estado cautivo de los tupíes y su exigencia a los carijós para hacerles la guerra, podría ser tomada como una venganza de parte del español. Pues es el mismo que, cuando estaban a punto de matarlo, fue liberado por el P. Manoel de Chaves, junto a una india que tenía por manceba y que los jesuitas quisieron casar, pero se negaron y les tomaron odio.

El P. Anchieta dedica unas líneas finales resaltando las virtudes de los mártires y agregando que el $\mathrm{P}$. Nóbrega tenía casi resuelto enviarlo con aquellos hermanos como compañero, pero dice él mismo: "mas fui indigno de os seguir". Finalmente, dedica varias otras líneas a ambos mártires. Correia: "tido entre os mais nobres deste reino", Sousa: "ja sedistinguia por grande probidade de vida". De este último poco se conoce. Aunque, por una carta donde se le paga al P. Manuel de Paiva, en ausencia del P. Nóbrega, 4.500 reis que se debían al soldado João de Sousa, sabemos que este último había sido militar y había servido al gobernador general Tomé de Sousa en Bahía. Entró en la Compañía en Sao Vicente el 31 de julio de 1550, después de haber dejado de ser soldado hacía nueve meses ${ }^{28}$ (LEITE, 1956, p. 295).

Este martirio, como tal, fue cuestionado por el P. Cristóvão de Gouveia, visitador del Brasil (1583-1589), después de la elogiosa publicación del P. Ribadeneira, a quien le manifestó que: " $E l$ Pedro Correa era hermano y no Padre; ni acá se piensa que fuesem mártires; porque yendo a predicar a los Carijós, un español los hizo matar por los propios indios, mas no in odium fidei." Pero, como acertadamente escribe el $\mathrm{P}$. Leite, el martirio no solo se recibe específicamente por la fe, sino

\footnotetext{
${ }^{27}$ Carta: Do Ir. José de Anchieta ao P. Inácio de Loyola, Roma. S. Vicente, fin de marzo de 1555.

${ }^{28}$ Carta: Mandado de Pagamento do soldo devido ao Ir. Joao de Sousa, S. Vicente. Bahía, 15 de setiembre de 1551.
} 
también por el cumplimiento de la ley divina en materia grave. Agrega que ambos murieron predicando el Evangelio, defendiendo la moral cristiana en una obra de paz y que solo en este aspecto su sacrificio debe considerarse como hecho para el engrandecimiento de Brasil.

\section{Conclusión}

El H. Correia era una persona de cierta erudición, no porque haya estudiado, sino por el hecho que tanto los PP. Nunes como Nóbrega, le encargaban a él que escribiera cartas sobre los hechos del Brasil a los pares y superiores de Portugal. Y lo hacía muy bien. También lo demuestra el conocimiento que tenía de obras religiosas como las que solicitó del malogrado doctor Constantino, entre otras, aunque en realidad se las podrían haber encargado sus superiores.

Pero la mayor virtud que poseía era el conocimiento de las costumbres y sobre todo de la lengua indígena, a tal punto, que era como un pasaporte para los jesuitas en su labor pastoral. Así como el H. António Rodrigues fue el primero que enseñó la lengua de los indígenas en Bahía a los jesuitas recién llegados, en el sur del Brasil y mucho antes, el H. Correia fue quien más conocía la lengua indígena por el contacto directo que tuvo antes de ingresar a la Compañía de Jesús. Aunque fue el P. João Azpilcueta Navarro, el primero que sabemos escribió un resumen de predicación en lengua tupí, el H. Correia fue el principal aportante, junto a los PP. Luiz de Grã y Leonardo do Vale, para que José de Anchieta, terminara publicando en 1595 su Arte de gramática...

Estas virtudes no alcanzaron para borrar su pasado como bandeirante y asesino de indígenas, por lo cual no llegó a alcanzar su sacerdocio. Su perdón debieron solicitarlo a la Santa Sede y seguramente se le hubiera otorgado, pues para la época no estaba mal visto que se mataran indígenas no cristianos.

En medio de esa solicitud llegó el martirio, esa muerte santa tan esperada que los jesuitas interpretaron como una validación divina de que no solo era posible la conversión cristiana, sino también una prueba que la Compañía de Jesús era su legítimo brazo ejecutor en América. Los verdaderos continuadores de la evangelización comenzada por el apóstol Santo Tomás, cuya historia en América los propios jesuitas revalorizaron y aumentaron con grandilocuencia con el mismo propósito.

Sin embargo, a algunos jesuitas les costaba considerar al $\mathrm{H}$. Correia como mártir. Efectivamente, cómo incluir en la galería de varones ilustres de la Compañía de Jesús a un 
esclavista, por más arrepentido de su vida pasada que estuviera. El P. Gouveira fue el primero en cuestionarlo, exponiendo la excusa que no era sacerdote y que no había sido muerte "in odium fidei". Así también lo entendió y negó, entre otros, Jorge Cardoso, quien entre 1652 y 1666 publicó en tres gruesos tomos, el "Agiologio lusitano" donde se exponen las biografías de "santos" y "Varones ilustres" de la iglesia del reino de Portugal y sus colonias. Pero sí, por ejemplo, publicó la historia de Inácio de Azevedo y sus compañeros. Posiblemente la omisión se deba a que ni él, ni su sucesor Caetano de Souza, llegaron a publicar los muertos de los meses de setiembre a diciembre. Además y en esa línea, podríamos señalar a nuestro contemporáneo diccionario de la Compañía de Jesús que tampoco los incluyó entre las personalidades jesuitas del mundo, aunque su contemporáneo Tarner lo haya valorizado.

Para el contexto de aquellos tiempos también puede haber influido que, ante las relaciones políticas con España y la casi inminente unificación de las Coronas, no sería bien visto que un español haya mandado a matar a un jesuita de origen portugués. Seguramente todas estas cuestiones debieron influir para que tampoco nunca se iniciara un merecido proceso canónico.

De todas formas, estas negaciones fueron parciales, en tanto que el martirio fue usado no solo y como dijimos como validación de la presencia jesuítica, sino también a lo largo del tiempo. Prueba de ello son las representaciones de las pinturas de la capilla de Santa Cecilia en San Pablo, donde ambas imágenes: el bandeirante arrepentido y el mártir, se unifican para convalidar la elite dominante. En tanto que la información y acompañamiento del H. Sousa quedó opacado ante la figura de Correia, como pasó con otros ejemplos similares.

\section{Referências}

CRETINEAU-JOLI, Jacques. Historia religiosa, política y literaria de la Compañía de Jesús. Barcelona: Imprenta de Pablo Riera, 1853. t. 1, p. 369.

FERNANDES, Maria de Lurdes Correia. Agiológico lusitano. Porto: Universidade do Porto: 2002. t. 5 .

GUERREIRO, Bertholæv. Gloriosa Coroa d. esforçados religiosos da Companhia de Iesu. Mortos polla fe catholica nas Conquistas dos Reynos da Coroa de Portugal. Lisboa: Antonio Alvarez del Rey, 1642.p. 306-310.

JARRIC, Pierre du. Histoire des choses plus memorables advenues tant ez Indes Orientales, que autres païs de la decouverte des Portugais, en l'establissement \& progrez de la foy Chrestienne E Catholique; Et principalement de ce que les Religieux de la Compagnie de Iesus y ont faict, E enduré 
par le mesme fin. Depuis qu'ils y sont entrez jusqu'a l'an 1600. Bordeaux: Simon Millanges, 1610. t. 1-2.

LEITE, Serafim. História da Companhia de Jesus no Brasil. São Paulo, 2004.

LEITE, Serafim. Monumenta historica societatis iesu. monumenta brasilae II (1553-1558). Roma: Monumenta Historica, 1957.

LEITE, Serafim. Monumenta historica societatis iesu. monumenta brasilae I (1538-1553). Roma: Monumenta Historica, 1956.

MAFFEII, Ioan Petri. Historiarvm indicarvm. Livri XVI. Selectarvm, Item, ex India, Epistolarum, eadem interprete, Livri IV. Coloniæ Agrippinae: Officina Birckmannica, 1593. p. 319-320.

MOURA SOBRAL, Luis. Pintura, santos y propaganda: la sacristía del antiguo colegio de los jesuitas de Salvador, Bahía. In: CONGRESO INTERNACIONAL DEL BARROCO AMERICANO: TERRITORIO, ARTE, ESPACIO Y SOCIEDAD, 3., 2001, Sevilla. Actas... Sevilla: Universidad Pablo de Olavide, 2001. p. 346.

NIEREMBERG, Iuan Eusebio. Firmamento religioso de lvzidos astros, en algvnos claros varones de la Compañia de Iesvs. Madrid: Maria de Quiñones, 1644. p. 489-493.

ORLANDINI, Niccolò. Historiae societatis iesu prima pars. Roma: Bartholomaum Zannedu, 1614. p. 485-487.

PAGE, Carlos A. El jesuita portugués Manuel Ortega y el agrupamiento de ybyrajáras cristianos en los inicios de la evangelización del Guayrá. Temas Americanistas, Sevilla-España, $\mathrm{n}^{\circ}$ 37, p. 24-42, 2016.

PAGE, Carlos A. La iconografía de los primeros mártires jesuitas de América. La validación de la presencia jesuítica en América y el accionar de los bandeirantes paulistas. XII Jornadas Estudios e Investigaciones, Universidad de Buenos Aires, Facultad de Filosofía y Letras, Instituto de Teoría e Historia del Arte "Julio E, Payró", Buenos Aires, 9 al 11 de agosto de 2017.

PHILIPPOV, Karin. A produção religiosa de Benedito Calixto e a ótica do mecenato religioso. In: ENCONTRO DE HISTÓRIA DA ARTE, 9., 2013, Campinas. Anais... Campinas: UNICAMO, 2013. p. 154.

RIBADENRYRA, Pedro. Vida del P. Ignacio de Loyola, fundador de la religión de la Compañía de Iesus: y de los Padres maestro Diego Laynez, y Francisco de Borja, segundo y tercero Preposito Grneral de la misma Compañía. En las quales se contiene su fundacion, progresso, aumento, hasta el año de 1572. Madrid: Por Pedro Madrigal, 1594. 
RODRIGUES, Francisco. História da companhia de Jesus na assistência de Portugal. A fundação da Provincia Poruguesa, 1540-1560. Porto: Apostolado da Imprensa XIV, 1931.

TANNER, Mathias. Societas Jesu usque as sanguinis et vitæ profusionem militans, in Europa, Africa, Asia, et America, contra gentiles, mahometanos, judæos, hæreticos, impíos, pro Deo, fide ecclesia, pietate. Sive vita et mors eorum. Praga: Typis Universitatis Carolo-Ferdinandæ, 1675. p. 438-440.

TELES, Baltasar. Chronica da companhia de Iesv da provincia de Portugal. Lisboa: Pavlo Craesbeeck, 1647. p. 501-506.

TOLEDO ROMANO, Cristina de. A igreja de Santa Cecília e as representações do bandeirante na obra de Benedito Calixto: percalços eclasiásticos em São Paulo, na primeira república. Revista Brasileira de História das Religiões, Maringá, ano 2, n. 4, maio, 2009.

VASCONCELlOS, Simão. Chonica da Companhia de Jesus do estado do Brasil e do que obraram seus filhos n'esta parte don novo mundo. Lisboa: Em casa do Editor A. J. Fernandes Lopes, 1865. v. 1, p. 97-104.

VASCONCELLOS, Simão. Vida do P. Joam D'Almeda da Companhia de Iesv, na Provincia do Brazil. Lisboa: Officina Craesbeeckiana, 1658. p. 57-64.

VASCONCELLOS, Simão. Vida do veneravel padre Ioseph de Anchieta. Lisboa: Officina de Ioam da Costa, 1672. p. 34-42.

Recebido em 28/02/2018

Aprovado em 16/04/2018 